\title{
Photocatalytic efficiency of titanium dioxide immobilized on PVP/AAc hydrogel membranes: A comparative study for safe disposal of wastewater of Remazol Red RB-133 textile dye
}

\author{
Hoda S. Hafez,, ${ }^{1,2}$ A. El-Hag Ali, ${ }^{3}$ and M. S. A. Abdel-Mottaleb ${ }^{1, \dagger}$ \\ ${ }^{1}$ Photoenergy Center, Faculty of Science, Ain Shams University, 11566 Abbassia, Cairo, Egypt \\ 2 Dessert Environment Research Institute, Sadat City, Menoufia University \\ 3 Polymer Chemistry Department, National Center for Radiation Research and Technology, \\ 3 Ahmed El-Zohor St., El-Zohor Distr., P.O. box 29, Nasr City, Cairo, Egypt
}

\begin{abstract}
The paper reports on the photocatalytic efficiency of $\mathrm{TiO}_{2}$ nanoparticles immobilized on polyvinyl pyrrolidone/acrylic acid (PVP/AAc) copolymer hydrogels, which are prepared by means of $\gamma$-rays induced homo- and copolymerization. The efficiency of immobilized photocatalyst is tested on a commercial textile dye namely Remazol Red RB-133. The results are compared with photocatalytic efficiencies of different types of non supported $\mathrm{TiO}_{2}$ photocatalysts such as aqueous slurries of colloidal $\mathrm{TiO}_{2}$ prepared by sol-gel technique, and commercially available Degussa P25. Although less efficient than nonsupported ones, the hydrogel supported $\mathrm{TiO}_{2}$ photocatalyst has the practical advantages of easy separation and removal from the reactors. This makes it a viable technique for the safe disposal of textile wastewater into the water streams.
\end{abstract}

\section{INTRODUCTION}

Nanostructured titania films possess an immense range of applications, e.g. in the field of optics [1], electrical insulation [2], photovoltaic solar cells [3], electrochromic displays [4], antibacterial coatings [5], photocatalytic reactors [6], high performance anodes in ion batteries [7], and for gas sensing [8]. It has been shown that some applications greatly benefited from a nanostructured phase for $\mathrm{TiO}_{2}$ that has been recently produced by several methods [9-11]. The sol-gel technique has attracted more attentions due to the intensive development of sol-gel technology and the certain advantages compared with other technologies like: low process cost, low temperature of heat treatment, high evenness of film and wide possibility to vary film properties by changing the composition of the solution, etc.

Hydrogels are water-swollen network (cross-linked structure) of hydrophilic homopolymer or copolymers. They acquire a great interest due to the facility of the incorporation of different chelating groups into the polymeric networks. Such polymeric hydrogels are promising materials in the field of water purification due to their chemical stability especially hydrolytic and thermal stability.

In this work, PVP/AAc copolymer hydrogels, prepared by means of $\gamma$-rays induced homo- and copolymerization are used as a substrate for immobilizing $\mathrm{TiO}_{2}$ and its photocatalytic activity is tested and compared with that of aqueous slurries of a freshly prepared colloidal $\mathrm{TiO}_{2}$ and Degussa P25.

†E-mail: solar@link.net

\section{EXPERIMENTAL}

\subsection{Materials and methods.}

- The commercially available reactive dye Remazol Red RB-133 (RR RB-133, of formula I and absorption spectrum in Figure 1 is obtained from DyStar.

- Titanium Dioxide Degussa P25 $\left(\mathrm{TiO}_{2}\right)$ has an average particle size of $21 \mathrm{~nm}$ and $99.5 \%$ of $\mathrm{TiO}_{2}$ content, from Degussa Hüls Company.

- Colloidal Titanium Dioxide (freshly prepared from the hydrolysis of titanium isopropoxide following the conventional methods reported in the literature).

- PVP/AAc gels of three different compositions [(100/0), $(80 / 20)$ and $(50 / 50)$ by weight] are obtained by radiation induced homo/copolymerization of mixtures of different molar ratios using ${ }^{60} \mathrm{Co}$ gamma rays at a dose rate $10.28 \mathrm{kGy} / \mathrm{h}$. All samples are washed in excess water to remove the unreacted component then dried.

$\mathrm{TiO}_{2}$ immobilization on the PVP/AAc copolymer hydrogels. The samples are prepared by the well established method of dip-coating [12]. The supports PVP/AAc gels are immersed in $25 \mathrm{ml}$ of highly concentrated solution of the colloidal $\mathrm{TiO}_{2}$ for 2 days. The gel samples were removed from solution and then dried in air. This procedure is repeated to obtain samples with increasing content of titania. 
(I)<smiles>CS(=O)(=O)OOCCS(=O)(=O)c1ccc(N=Nc2c(S(=O)(=O)O)cc3cc(S(=O)(=O)O[Na])cc(Nc4nc(Cl)nc(Nc5ccc(S(C)(=O)=O)cc5)n4)c3c2O)cc1</smiles>

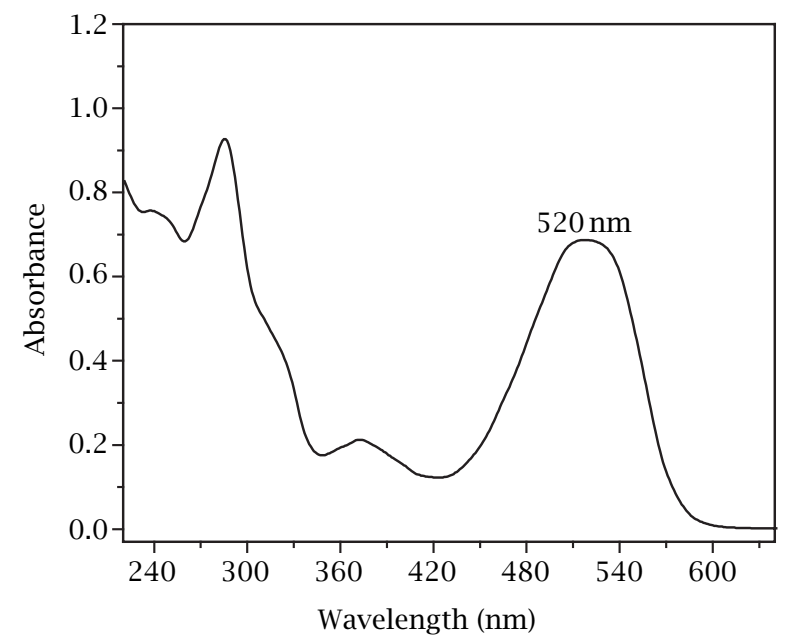

Figure 1. The electronic absorption spectrum of the reactive dye $R R R B-133$ in aqueous solution.

Chemical analysis of titanium oxide [13]. Following the literature method [13], a sample of $0.3 \mathrm{~g}$ of the supported photocatalyst is treated with $17 \mathrm{ml}$ mixture of concentrated acid $\mathrm{H}_{2} \mathrm{SO}_{4}$ and $\left(\mathrm{NH}_{4}\right)_{2} \mathrm{SO}_{4}$, $\left(\mathrm{H}_{2} \mathrm{SO}_{4}:\left(\mathrm{NH}_{4}\right)_{2} \mathrm{SO}_{4}=129: 30\right.$ by weight $)$ and boiled for $10 \mathrm{~min}$. The titanium oxide dissolved down and several drops of hydrogen peroxide are added to the resulting supernatant to develop color and the solution's absorbance at $410 \mathrm{~nm}$ is recorded. The dependence of the absorbance on the concentration of titanium is linear. In this paper, Ti content is reported in $\mathrm{mg} / \mathrm{g}_{\text {polymer }}$.

Adsorption kinetic studies. The experiments of the adsorption kinetics of the RR RB-133 on the $\mathrm{TiO}_{2}$ nanoparticles supported on the (PVP/AAc) copolymer hydrogels have been carried out by mixing $100 \mathrm{ml}$ of $5 \times 10^{-5} \mathrm{M}$ of the dye with $0.3 \mathrm{~g}$ of the copolymer hydrogel. At various time intervals, $t$, aliquot of the solution is taken and the remaining dye concentration in the solution is subsequently monitored by UV-Visible absorption spectroscopy until the absorbance values at $\lambda_{\max }=520 \mathrm{~nm}$ remained constant. The initial and equilibrium dye concentrations are determined using a calibration curve based on absorbance at $\lambda_{\max }$ versus dye concentration in standard dye solutions. The amount of dye adsorbed per unit mass of the copolymer hydro- gel at time $t, q_{t}(\mathrm{mg} / \mathrm{g})$, is calculated by using eq. (1) $[14,15]$

$$
q_{t}=\left(C_{0}-C_{t}\right) V / M
$$

where $C_{0}$ and $C_{t}(\mathrm{mg} / \mathrm{L})$ are the liquid phase concentrations of dye initially and at time $t$, respectively, $V$ is the volume of dye solution (L), and $M$ is the weight of adsorbent used (g). The adsorption experiments are continued until the equilibrium concentration has been reached.

2.2. Instrumentations. The experiments are carried out in a batch-type photocatalytic reactor identical to that described in ref. [16]. Irradiations are carried out using Xenon arc lamp (PTI-LPS-220 Photon Technology International) adjusted at 70 Watt. The radiation from this lamp was filtered through a water circulation that reduced incident warming by infrared radiation. Total UV-Visible incident radiation flux is measured with a radiometer from International Light Company (IL1700), using a detector that detects the radiation in the range (300-400 nm). The $\mathrm{pH}$ of the solution is adjusted using a dilute perchloric acid. The suspension is first stirred in the dark for about $90 \mathrm{~min}$ before irradiation to start the reaction at the adsorption equilibrium. 
Table 1. The equilibrium (\%) swelling of the PVP/AAc hydrogels in colloidal $\mathrm{TiO}_{2}$ solution ( $\mathrm{pH} 2.7$ ).

\begin{tabular}{lcc}
\hline (PVP/AAc) & $\begin{array}{c}\text { S(\%) } \\
\text { composition }\end{array}$ & $\begin{array}{c}{\left[\mathrm{TiO}_{2}\right]} \\
\mathbf{m g} / \mathbf{g}_{\text {polymer }}\end{array}$ \\
\hline $\mathbf{( 5 0 / 5 0 )}$ & 62 & 10.0 \\
$\mathbf{( 8 0 / 2 0 )}$ & 1100 & 16.6 \\
$\mathbf{( 1 0 0 / 0 )}$ & 2500 & 33.3 \\
\hline
\end{tabular}

A Unicam UV-Visible, double-beam, spectrophotometer from Helios Company has been used for the determination of the variations of the dye concentrations at $\lambda_{\max }=520 \mathrm{~nm}$.

\section{RESULTS AND DISCUSSION}

3.1. Effect of the extent composition of PVP on the swelling behavior of the hydrogel and its $\mathrm{TiO}_{2}$ up-

take. The effect of the acidic solution of the colloidal $\mathrm{TiO}_{2}$ on the swelling behavior of the different composites of the PVP/AAc hydrogels and the uptake amount of $\mathrm{TiO}_{2}$ has been reported, (Table 1). The swelling ratio $(S)$ is determined from the following equation:

$$
S=\frac{W_{s}-W_{o}}{W_{o}} \times 100
$$

where $W_{s}$ and $W_{o}$ are the weights of the swollen and the dry hydrogels, respectively.

The results in Table 1 show that the swelling behavior of the copolymer is greatly influenced by its composition. This is due to the increase of PVP content that leads to a decrease in the number of the associated carboxylic groups of the AAc and to a consequent decrease of the number of intermolecular hydrogen bonding, which gives a space for the PVP chains to swell freely in water [17].

Moreover, the amount of the $\mathrm{TiO}_{2}$ uptake by the different compositions of the PVP/AAc hydrogels increases with increasing the PVP content (Table 1). We can conclude that: as the AAc content in the hydrogel decreases, the swelling ability of the hydrogel at low $\mathrm{pH}$ values increases, and as a result, the possibility of the $\mathrm{TiO}_{2}$ uptake increases.

3.2. Adsorption kinetics. In heterogeneous photocatalytic degradation process the adsorption of dye onto the catalytic surface is the primary step of the reaction. The adsorption experiments were carried out in order to evaluate the rate constants of adsorption.

The kinetics of dark adsorption of RR RB-133 on titanium dioxide supported on the different composites of (PVP/AAc) copolymer gels are represented in Figure 2, where the amount of the dye adsorbed, $q_{t}$ in $\mathrm{mg} / \mathrm{g}_{\text {cat }}$, on the photocatalyst surface has been plotted as a function of time. The results show that the quantity adsorbed increases and reaches a value near saturation level as the time of equilibrium increases. From

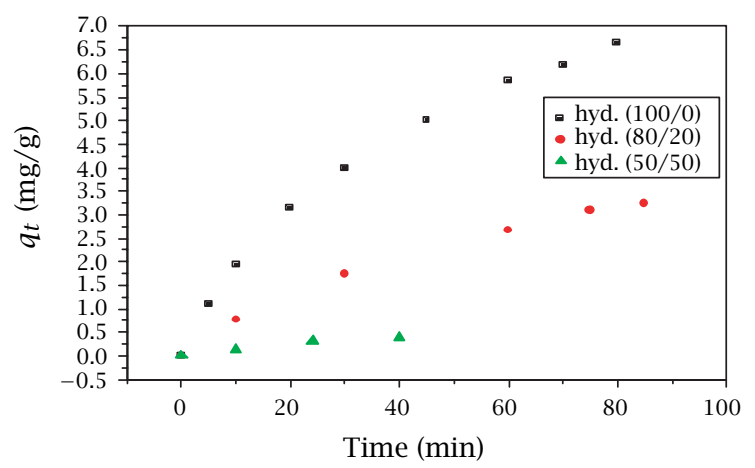

Figure 2. Kinetics of adsorption of the $R R R B-133$ dye. Experimental conditions: $\mathrm{pH}=2.7$; weight of $\mathrm{TiO}_{2}=0.3 \mathrm{~g}$; $V=0.1 \mathrm{~L}$.

Table 2. Adsorption kinetics of RR BR-133 dye on different (PVP/AAc) hydrogels.

\begin{tabular}{|c|c|c|}
\hline $\begin{array}{l}\text { (PVP/AAc) } \\
\text { composition }\end{array}$ & $\begin{array}{c}\mathbf{q}_{\max } \\
\left(\mathbf{m g} / \mathbf{g}_{\text {cat }}\right)\end{array}$ & $\begin{array}{c}\mathrm{k} \times 10^{-3} \\
\left(\min ^{-1}\right)\end{array}$ \\
\hline$(50 / 50)$ & 0.38 & 0.6 \\
\hline$(80 / 20)$ & 3.23 & 2.4 \\
\hline$(100 / 0)$ & 6.66 & 6.2 \\
\hline
\end{tabular}

the data in Figure 2, it is possible to determine the maximum quantities $q_{\max }$ of the dye adsorbed per gram of catalyst at equilibrium (Table 2).

A simple kinetic analysis of adsorption is the firstorder equation. Ho and McKay [18] have compiled an extensive list of publications that employed the firstorder reaction rate expression to describe the adsorption of organic compounds on a variety of adsorbent materials. Our data fit the following first-order rate equation $[19,20]$ :

$$
\ln \left(C_{t}-C_{e}\right)=-k t+\text { constant }
$$

where $k\left(\mathrm{~min}^{-1}\right)$ is the first-order rate constant, $C_{t}$ is the concentration of the dye in the solution at time $t$ and $C_{e}$ is the concentration at equilibrium. Plotting $\ln \left(C_{t}-C_{e}\right)$ versus time in minutes gives good linear plots (Figure 3 ). The obtained numerical data have been summarized in Table 2.

It is obvious, from the results in Table 2, that both the maximum quantity of the dye adsorbed at equilibrium $q_{\text {max }}$ and the rate of adsorption $k$ increase with the increase of the amount of the $\mathrm{TiO}_{2}$ uptake as a consequence of increasing PVP content in the hydrogels.

3.3. Photocatalytic activity. The results of a blank experiment in the absence of the photocatalyst showed that negligible decolorization of the dye solution by $\mathrm{UV} /$ Vis irradiation is observed.

The photocatalytic activity of $\mathrm{TiO}_{2}$ immobilized on the different composites of the studied hydrogels has been tested by following up the decolorization rate of 


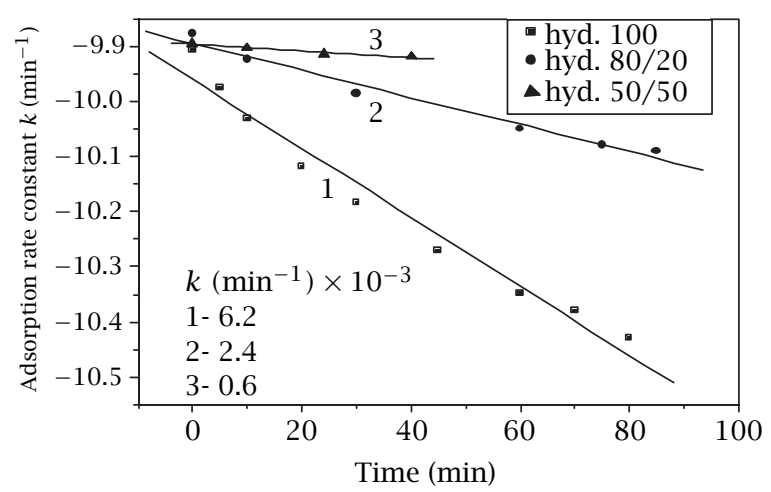

Figure 3. The kinetic plots of the adsorption of the $R R$ RB-133 on the $\mathrm{TiO}_{2}$ supported on: (1) 100 PVP, (2) 80/20 PVP/AAc and (3) 50/50 PVP/AAc copolymer hydrogels.

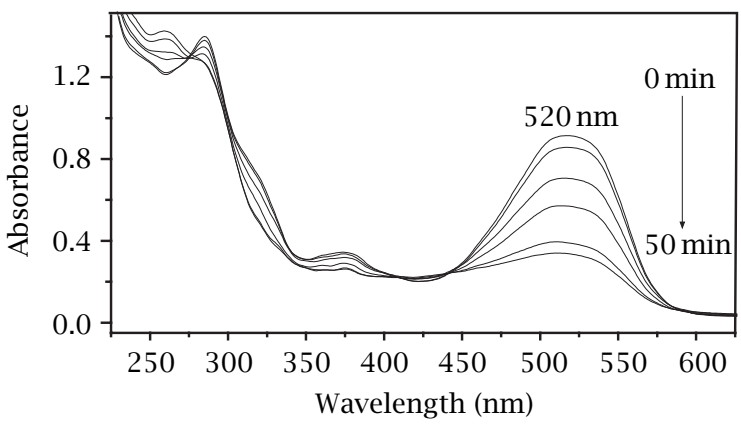

Figure 4. Irradiation-induced changes of the absorption spectrum of $R R R B-133$ in presence of $\mathrm{TiO}_{2}$ immobilized on PVP/AAc (80/20) gels membranes.

Table 3. Photodegradation rate constants of RR RB-133 using $\mathrm{TiO}_{2}$ supported on the different PVP/AAc hydrogels.

\begin{tabular}{lc}
\hline $\begin{array}{l}\text { PVP/AAc) } \\
\text { composition }\end{array}$ & $\begin{array}{c}\text { Rate constant } \times \mathbf{1 0}^{-\mathbf{1}} \\
\left(\mathbf{m i n}^{-1}\right)\end{array}$ \\
\hline $\mathbf{( 5 0 / 5 0 )}$ & 0.06 \\
$\mathbf{( 8 0 / 2 0 )}$ & 0.20 \\
$\mathbf{( 1 0 0 / 0 )}$ & 0.35 \\
\hline
\end{tabular}

$100 \mathrm{~mL}$ of $5 \times 10^{-5} \mathrm{M}$ of RR RB-133. The color bleaching is measured in terms of absorbance values at $520 \mathrm{~nm}$ as shown in Figure 4. All the reactions followed a first order kinetics, confirmed by the linear transforms $\ln \left(A_{520 \mathrm{~nm}}\right)=f(t)$ illustrated in Figure 5. Moreover, the decolorization rates of the dye solution with the $\mathrm{TiO}_{2}$ thin film coated on the three different composites of the hydrogels (100/0), (80/20) and (50/50) are compared with their pure hydrogels as shown in Figure 5 and Table 3.

From the preliminary experiments, we have found that the pure hydrogels without photocatalyst have a negligible effect on the color bleaching of the dye.

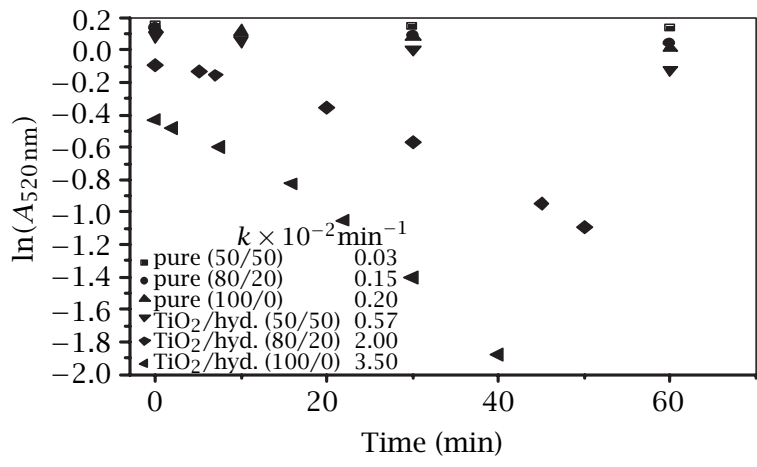

Figure 5. Photodegradation $[\ln (A)$ - time] rate kinetics of $R R R B-133$ using $\mathrm{TiO}_{2}$ supported on different composites of PVP/AAc copolymers in comparison with the corresponding pure hydrogels, Conditions: $0.3 \mathrm{~g}$ hydrogel loaded with $\mathrm{TiO}_{2}$ and $\mathrm{pH}=3.5-4.3$.

Table 4. Photodegradation rate constants of $5 \times 10^{-5} \mathrm{M} R R$ $R B-133$ using different $\mathrm{TiO}_{2}$ forms under the same experimental conditions.

\begin{tabular}{l|ccc}
\hline $\begin{array}{l}\text { Different } \\
\text { forms of } \\
\mathrm{TiO}_{2}\end{array}$ & $50 / 50$ & $\begin{array}{c}\text { Rate constant } \times 10^{-3} \\
\left(\mathrm{~min}^{-1}\right)\end{array}$ \\
\hline $\mathrm{TiO}_{2} / \mathrm{Hyd}$. & 06 & $20 / 20$ & $100 / 0$ \\
$\mathrm{TiO}_{2}$ Deg. & 30 & 47 & 35 \\
$\mathrm{TiO}_{2}$ Coll. & 42 & 58 & 60 \\
\hline
\end{tabular}

Moreover, the results show that the photocatalytic efficiency increases with increasing the PVP content, as the amount of the $\mathrm{TiO}_{2}$ uptake increases with increasing the PVP content.

3.4. Comparison of different photocatalysts. The photocatalytic activity of the $\mathrm{TiO}_{2}$ thin film coated on the copolymer hydrogels has been tested in comparison with the same amount of $\mathrm{TiO}_{2}$ in forms of: (1) an aqueous slurry of a freshly prepared colloidal $\mathrm{TiO}_{2}$ and (2) commercially available Degussa P25 (as shown in Figure 6 and Table 4).

Under the same experimental conditions (equal amount of $\mathrm{TiO}_{2}$ and $\mathrm{pH}$ ) the PVP/AAc hydrogelsupported catalysts are of about $58 \%$, and $35 \%$ efficient relative to the non-supported ones the commercially available Degussa P25 and freshly prepared colloidal photocatalysts, respectively.

3.5. Re-use of the supported $\mathrm{TiO}_{2}$ on the copolymer hydrogel. Three photodegradation experiments are performed without changing the catalyst, which just washed with water between each experiment. The determined rates of photobleaching of the dye with the same photocatalyst are: $0.02,0.018$ and $0.009 \mathrm{~min}^{-1}$ for the first, second and third experiment. Thus, the supported $\mathrm{TiO}_{2}$ on the copolymer hydrogel could be used for two or maximum of three times 


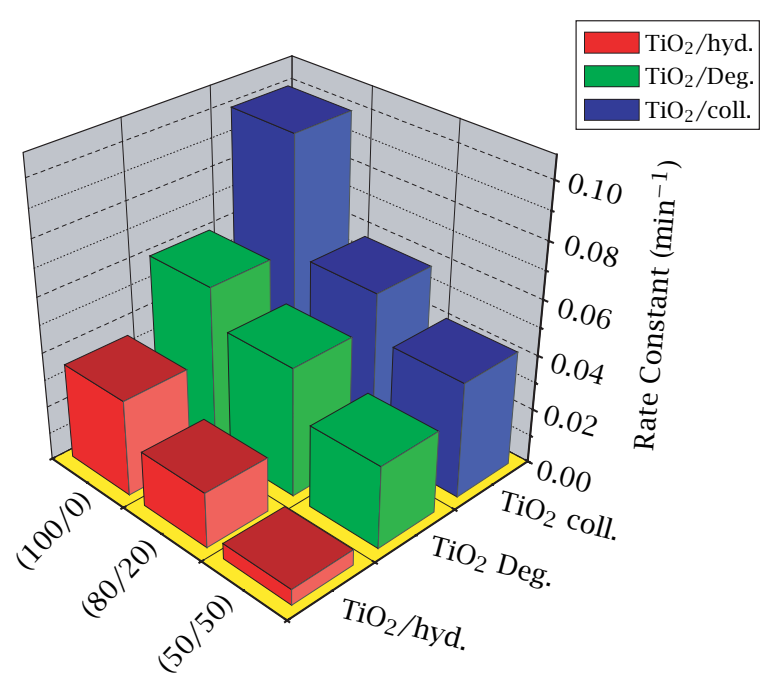

Figure 6. Comparison of the photodegradation rates of $R R$ RB-133 using the same amounts of: $\mathrm{TiO}_{2}$ supported on hydrogels; suspended $\mathrm{TiO}_{2}$ Degussa P25 and colloidal $\mathrm{TiO}_{2}$.

before it becomes inefficient. This effect is attributed to the deactivation of the catalyst surface by the byproducts of the degradation of the dye and or polymer degradation by the deposited titania [21]. Further research works are undertaken to test regeneration of the hydrogel supported catalysts.

\section{CONCLUSIONS}

It has been shown that the amount of the $\mathrm{TiO}_{2}$ uptake in acidic medium increases with increasing PVP content due to increasing the swelling degree of the copolymer hydrogels. Thus, leads to increasing the adsorption as well as the photodegradation rate constants of the RR RB-133.

Under the same experimental conditions (equal amount of $\mathrm{TiO}_{2}$ and $\mathrm{pH}$ ) the PVP/AAc hydrogelsupported catalysts is about $58 \%$ and $35 \%$ efficient relative to the non-supported ones the commercially available Degussa P25 and freshly prepared colloidal photocatalysts, respectively. However, the practical advantages of ease of separation and removal of such a supported catalyst from the reactors, makes it a viable technique for the safe disposal of textile wastewater into the water streams.

\section{ACKNOWLEDGMENT}

The work is carried out in the framework of the AQUACA project supported by the EU under the contract number: ICA3-CT2002-10016.

\section{REFERENCES}

[1] H. Tang, K. Prasad, R. Sanjinés, and F. Lévy, Sens. Actuators B 26 (1995), 71.

[2] K. Bange, C. R. Ottermann, O. Anderson, U. Jeschkowsky, M. Laube, and R. Feile, Thin Solid Films 197 (1991), 279.

[3] B. O. Regan and M. Graetzel, Nature 353 (1991), 737.

[4] T. Gerfin, M. Graetzel, and L. Walder, Prog. Inorg. Chem. 44 (1997), 345.

[5] X. Marguerettaz and D. Fitzmaurice, J. Am. Chem. Soc. 116 (1994), 5017.

[6] K. Sunada, Y. Kikuchi, K. Hashimoto, and A. Fujishima, Environ. Sci. Technol. 32 (1998), 726.

[7] S. Y. Huang, L. Kavan, I. Exnar, and M. Graetzel, J. Electrochem. Soc. 142 (1995), L142.

[8] M. Ferroni, V. Guidi, G. Martinelli, P. Nelli, and G. Sberveglieri, Sens. Actuators B 44 (1997), 499.

[9] G. Sberveglieri, L. E. Depero, M. Ferroni, V. Guidi, G. Martinelli, P. Nelli, C. Perego, and L. Sangaletti, Adv. Mater. 8 (1996), 334.

[10] A. R. Bally, E. N. Korobeinikova, P. E. Schmid, F. Lévy, and F. Bussy, J. Phys. D, Appl. Phys. 31 (1998), 1149.

[11] M. C. Carotta, M. Ferroni, V. Guidi, and G. Martinelli, Adv. Mater. 11 (1999), 943.

[12] J. M. Herrmann, H. Tahiri, C. Guillard, and P. Pichat, Catal. Today 54 (1999), 131.

[13] C. Hu, Y. Wang, and H. Tang, Appl. Catal. B: Environ. 30 (2001), 277.

[14] M. Chairat, S. Rattanaphania, J. B. Bremner, and V. Rattanaphani, Dyes and Pigments 64 (2005), 231.

[15] F. Akbal, J. Coll. and Inter. Sci. (2005), article in press.

[16] A. A. Essaway and M. S. A. Abdel-Mottaleb, Intern. J. Photoenergy 5 (2003), 219.

[17] A. El-Hag Ali, H. A. Shawky, H. A. Abd El-Rehim, and E. A. Hegazy, European Polymer J. 39 (2003), 2337.

[18] Y. S. Ho and G. A. McKay, Trans. Inst. Chem. Eng. B 76 (1998), 332.

[19] N. Naime, A. lu, F. Kar, and N. Arslan, J. Food Eng. (2004), article in press.

[20] M. Todorovic, S. K. Milonjic, and J. J. Comor, Sep. Sci. Technol. 27 (1992), 671.

[21] K. Venkata Subba Roa, M. Subrahmanyam, and P. Boule, Appl. Catal. B: Environ. 49 (2004), 239. 


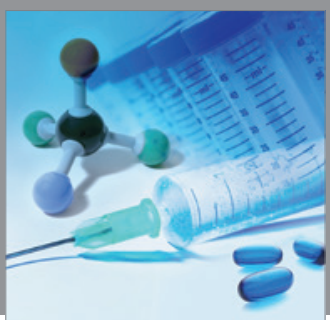

International Journal of

Medicinal Chemistry

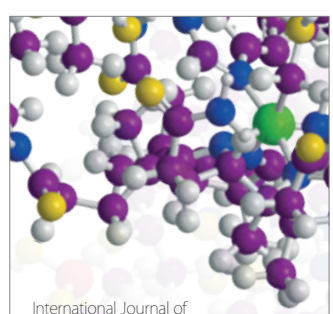

Carbohydrate Chemistry

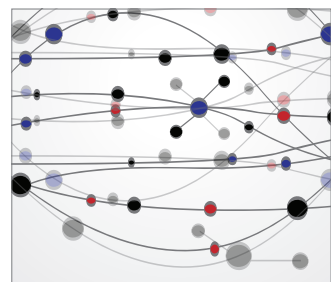

The Scientific World Journal
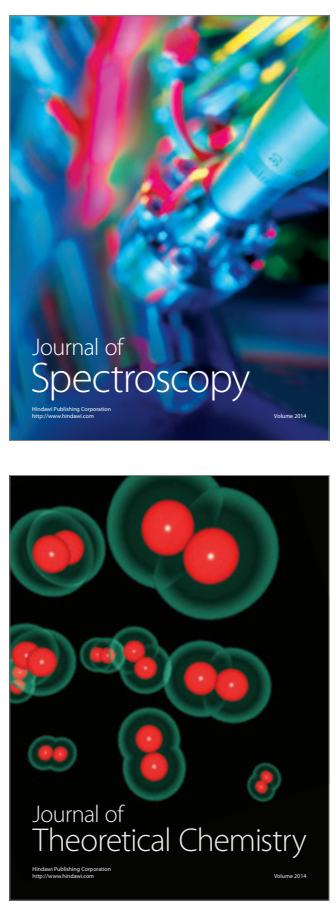
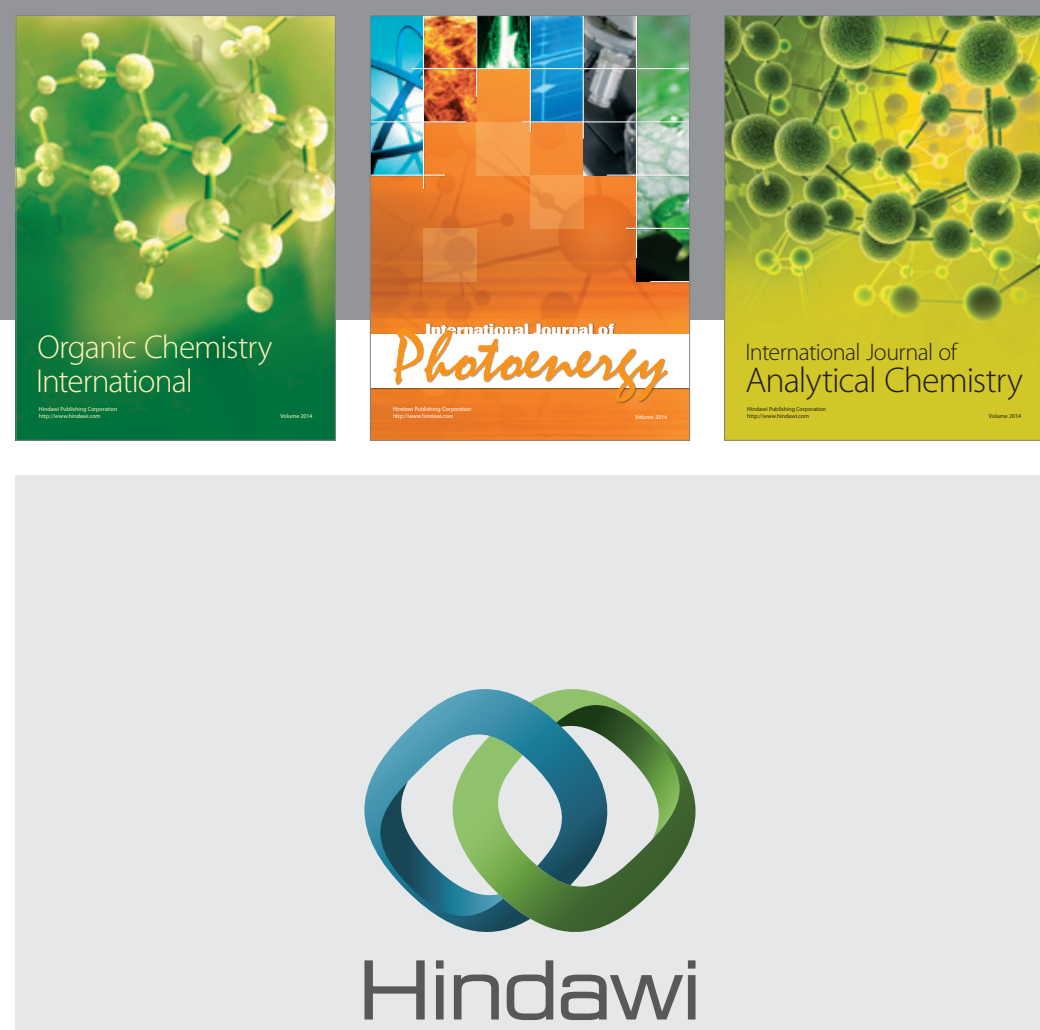

Submit your manuscripts at

http://www.hindawi.com
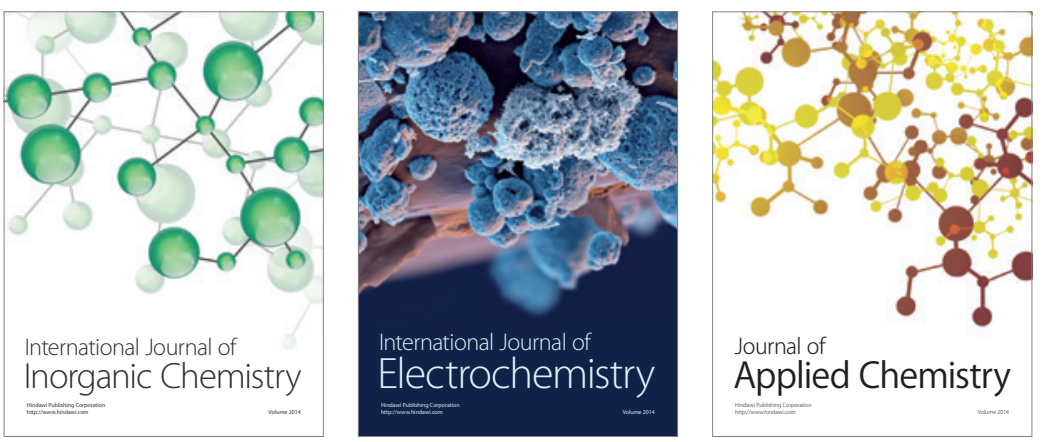

Journal of

Applied Chemistry
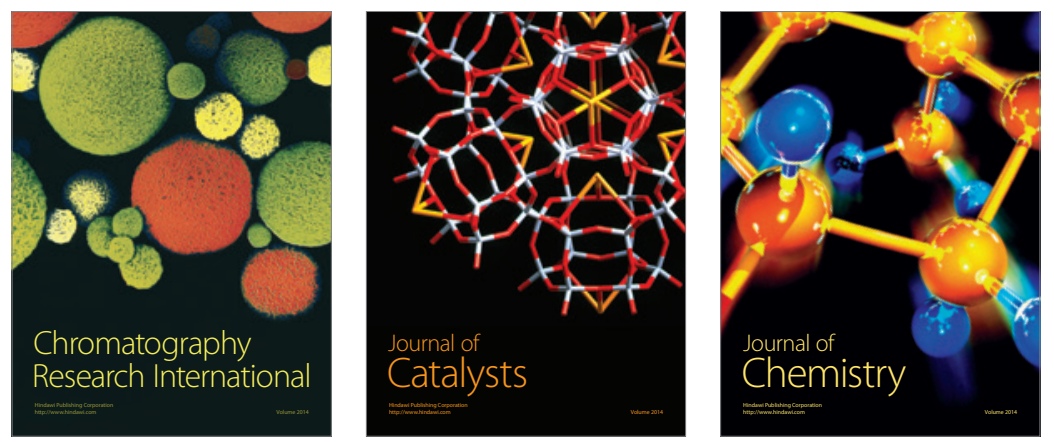
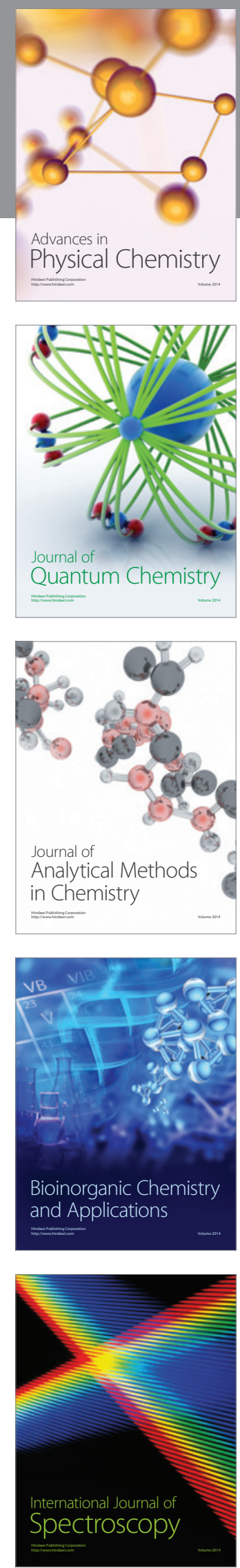